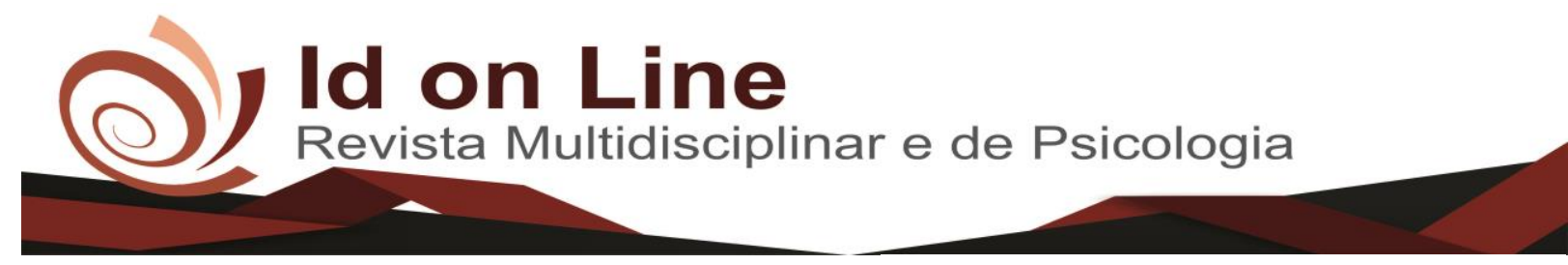

Artigo

\title{
A Percepção dos Moradores Locais sobre os Impactos Socioambientais Gerados Após as Instalações das Indústrias Calçadistas no Município de Brejo Santo-CE
}

Jairo Grangeiro Patriciol ${ }^{\text {; Raniel Silva Lima² }}$

\begin{abstract}
Resumo: As metas dos empresários em produzir mais e mais com o objetivo apenas de obter lucros sem qualquer preocupação com o meio ambiente causou vários danos ao meio ambiente em geral, hoje em dia a visão é outra, as preocupações com socioambientais são nítidas em várias organizações. O objetivo da pesquisa trata em compreender a percepção que a população da cidade de Brejo Santo-CE tem a respeito dos impactos socioambientais provocados após as instalações das indústrias calçadistas no município, descrever as percepções da população local acerca dos impactos que a industrialização provoca; analisar diante da percepção da população se as indústrias promovem ações socioambientais e entender como a sociedade se porta diante dessas possíveis alterações socioambientais. Foi realizada uma pesquisa exploratória descritiva, com um questionário aplicado a uma amostra de 270 pessoas. Apesar da maioria dos entrevistados terem uma visão restrita a esse processo de industrialização, fica nítido que tais indústrias não usam da estratégia de promoverem ações socioambientais, sendo que neste ponto não houve mudanças e nem qualquer alteração a serem percebidas pela sociedade.
\end{abstract}

Palavras Chave: Percepção, Sustentabilidade, Gestão ambiental

\section{The Perception of Local Residents on the Socio-Environmental Impacts generated after the Installations of the Footwear Industries in the Municipality of Brejo Santo, State of Ceará}

\begin{abstract}
The goals of entrepreneurs in producing more and more with the goal of just making profits without any concern for the environment has caused various damages to the environment in general, nowadays the vision is another, social-environmental concerns are clear in several organizations. The objective of the research is to understand the perception that the population of the city of Brejo Santo-CE has about the socio-environmental impacts caused after the installations of the footwear industries in the municipality, to describe the perceptions of the local population about the impacts that the industrialization causes; to analyze before the perception of the population if the industries promote socio-environmental actions and to understand how the society bears before these possible socio-environmental changes. A descriptive exploratory study was carried out, with a questionnaire applied to a sample of 270 people. Although most of the interviewees have a restricted view of this process of industrialization, it is clear that such industries do not use the strategy of promoting social and environmental actions, and at this point there were no changes and no changes to be perceived by society.
\end{abstract}

Keywords: Perceptions, Sustainability, Environmental Management.

\footnotetext{
${ }^{1}$ Graduando do curso de Administração no Centro Universitário Dr. Leão Sampaio/UniLeão - jairo777g@ hotmail.com.br;

2 Professor orientador do Centro Universitário Dr. Leão Sampaio/UniLeão - especialista em Gestão Financeira.

Contato: raniel@leaosampaio.edu.br.
} 


\section{Introdução}

No decorrer dos últimos anos o planeta vem sofrendo com a ação do homem em diversas práticas que agridem ao planeta, pois as metas dos empresários era em produzir mais e mais com o objetivo apenas de obter lucros sem qualquer preocupação com o meio ambiente ocorrendo diversas alterações ambientais no mundo inteiro, diante disso começou uma cultura de preocupação com questões ambientais, principalmente as indústrias que são as mais vistas como o meio que mais agride ao meio ambiente, pois geram bastantes resíduos em qualquer que seja seu segmento, daí vem a necessidade das empresas e indústrias apostarem na responsabilidade social como uma forma de serem mais aceita no mercado (PEREIRA et al. 2017).

Grandes indústrias calçadistas estão instaladas no Nordeste, visando vantagens financeiras e competitivas de mercado, a exemplo da região do cariri sendo o maior polo calçadista do Nordeste segundo Cariri (2017), consequentemente isso faz com que se produzam muitos resíduos sólidos de várias naturezas.

Diante desse contexto vem o seguinte questionamento: qual a percepção dos moradores de Brejo Santo-CE sobre os impactos socioambientais gerados após as instalações e funcionamento das indústrias calçadistas no município?

A gestão para a sustentabilidade possui como principal argumento a integração de aspectos econômicos, sociais e ambientais na estratégia e operações das empresas, isso representa um desafio cada vez mais complexo de ser gerenciado, porem tal desafio está associado com a obtenção de vantagens competitivas pelas organizações (DA ROCHA, 2015).

O impacto ambiental é consequência da ação do homem, por isso é importante que a sociedade seja educada para que tenham comportamentos responsáveis que causem menos impactos agressivos ao meio ambiente (SÁNCHEZ, 2015).

Muito se falou e ainda vem se falando muito sobre meio ambiente no Brasil, entretanto ainda não é tão notória a exata percepção que as pessoas evidenciam sobre o assunto, basicamente com relação a concreta dimensão das variáveis ambientais e suas causas sobre o ambiente como um todo (FERNANDES et al. 2004), diante disso, o presente artigo tem como principal objetivo compreender a percepção que a população da cidade de Brejo Santo-CE tem 
a respeito dos impactos socioambientais provocados após as instalações das indústrias calçadistas no município. E tem como objetivos secundários: descrever as percepções da população local sobre os impactos que a industrialização provoca; analisar diante da percepção da população se as indústrias promovem ações socioambientais e entender como a sociedade se porta diante dessas possíveis alterações socioambientais.

A realização dessa pesquisa foi instigada em compreender sobre a percepção dos moradores de um município pequeno sobre o aumento da industrialização e impactos gerados ambientais gerados pelo funcionamento dessas indústrias, no qual o conhecimento alcançado durante a pesquisa proporcionara um conhecimento de teórico e prático de bastante relevância na vida profissional do pesquisador, trazendo resultados bastante interessantes de ser visto pelas indústrias instaladas nesse município, esse estudo servirá como fonte de pesquisa para outros pesquisadores discentes e docentes.

\section{Gestão Ambiental}

Para Barbieri (2004) Gestão Ambiental são todas as atividades administrativas e operacionais que a empresa realiza para abordar problemas ambientais consequentes de sua atuação ou tudo que a empresa pratica para evitar que elas ocorram no futuro.

A Gestão Ambiental é a forma pela qual a empresa busca atingir suas metas ambientais, se mobilizando interna e externamente na busca pela qualidade ambiental exigida, visando o menor custo. O Sistema de Gestão Ambiental (SGA) promove políticas organizacional, partindo dos requisitos da legislação ambiental ISSO 14000. No cenário atual a tendência é que as empresas façam da sua política ambiental um fator diferencial e competitivo no mercado (RABELO, 2016).

Gestão ambiental é uma das áreas da administração empresarial que dar ênfase à sustentabilidade, prevendo o uso de práticas e métodos administrativos para reduzir ao máximo o impacto ambiental gerado das atividades econômicas nos recursos naturais (PORTAL EDUCAÇÃO, 2017)

Esse raciocínio segue na mesma linha de pensamento usada por NILSON (1998) que segundo ele a Gestão ambiental envolve planejamento, organização, e orienta a empresa a 
alcançar suas metas ambientais especificas, comparando por exemplo com o que ocorre com a gestão de qualidade.

Jabbour et al. (2012) se refere à Gestão ambiental como uma integração de objetivos e estratégias ambientais aos objetivos e estratégias mais importantes da organização, NILSON (1998) sendo de um total compromisso corporativo e por vez sua introdução requer decisões nos níveis mais elevados da administração.

A Gestão Ambiental é a forma pela qual a empresa busca atingir suas metas ambientais, se mobilizando interna e externamente na busca pela qualidade ambiental exigida, visando o menor custo. O SGA promove políticas organizacional, partindo dos requisitos da legislação ambiental ISSO 14000. No cenário atual a tendência é que as empresas façam da sua política ambiental um fator diferencial e competitivo no mercado (RABELO, 2016).

No contexto de Schenini (2005), a adoção de medidas ambientalmente corretas é instigada por interesses internos e externos das organizações. Dentre as razões internas estão a diminuição de custos, a atualização tecnológica, a otimização nos processos produtivos e o desenvolvimento de uma cultura interna ecologicamente correta.

Mello et al. (2015) sintetiza que já faz parte da realidade das empresas industriais que a Gestão Ambiental é necessária para que estas se adaptem as exigências imperativas de mercado.

Quando uma empresa coloca no mercado um produto que mostra sua preocupação com o meio ambiente, este produto juntamente com a empresa ganha respaldo no meio empresarial (PORTAL EDUCAÇÃO, 2017).

Nesses processos de renovação e de adaptação das empresas a gestão ambiental mecanismo como a gestão proativa tem ajudo os empresários a lidar com problemas ambientais (MELLO et al. 2015). O Sistema de Gestão Ambiental (SGA) está sendo implantada nas organizações como um fator estratégico para que seja elevada a competitividade e posteriormente conquistar a confiança dos stakeholders (MARANHÃO, 2015).

\section{Percepção Ambiental}

É o procedimento no qual o sujeito seleciona, organiza e interpreta a informação para dar sentido ao mundo. Nossas experiências passadas, crenças, atitudes, valores, personalidades 
isso varia muito de como percebemos as coisas ao nosso redor, faz com que nossa percepção sobre alguma coisa seja diferente de outras pessoas. A percepção irá variar conforme as necessidades de cada indivíduo (DIAS; DA CRUZ, 2015).

Os estudos da percepção consideram a pessoa como um organismo biológico, social e indivíduo único, assim são entendidos como um processo mental seletivo pelo qual os homens se relacionam com o mundo, a partir das sensações transmitidas ao cérebro pelos sentidos. A percepção desenvolve através da funcionalidade dos sentidos, assim gerando um resultado diferente em cada indivíduo, os estímulos sensoriais é o que distingue a forma como cada pessoa compreende a realidade (SANTOS, 2018).

\section{Educação Ambiental}

A educação ambiental surge como um argumento de trabalho, dentro dos espaços formais e não formais de educação, representa uma forma de entender a importância de analisar e discutir desde a extração de recursos naturais passando pelo seu processo de industrialização até o seu consumo, descarte, notando os impactos ambientais e os agravos ao meio ambiente que cada fase pode ocasionar (DE FERREIRA; DE MIRANDA; GOMES, 2015).

Cada pessoa percebe, reage e responde de forma diferente às ações do o ambiente em que vive, os resultados ou manifestações decorrentes disso são os resultados das percepções, dos processos e expectativas de cada indivíduo. Assim a percepção ambiental pode ser determinada como uma forma de perceber o ambiente em que está vivendo, compreendendo que tem de proteger e a cuidá-lo (FERNANDES et al. 2004).

Quando pensamos em educação ambiental, nos referimos ao seu contexto mais amplo, o de educação para a cidadania, caracterizando como elemento determinante para consolidação de sujeitos cidadãos sendo atores corresponsáveis na defesa da qualidade de vida. A solidariedade, a igualdade e o respeito as diferenças devem ser a busca da educação ambiental isso se unifica no objetivo de criar novas atitudes e comportamentos diante do consumo de nossa sociedade (JACOBI, 2003).

A percepção ambiental pode ser aplicada para calcular a degradação ambiental de uma certa localidade, ajudando a reaproximar a população da natureza, estimando um futuro com 
qualidade de vida para todos nós, já que desperta uma enorme responsabilidade nos indivíduos acerca do ambiente que estão inseridos (FERNANDES et al. 2004).

A educação ambiental associada a percepção ambiental, precisam ter de objetivo a passagem de conhecimento e a compreensão dos problemas ambientais, provocando maior sensibilidade nas pessoas diante da preservação dos recursos naturais e na preservação de acidentes ambientais que afetem a qualidade de vida da população. (MELAZO, 2005).

A Educação Ambiental é um procedimento permanente que objetiva a formação da opinião cidadã e ambiental dos atores sociais, usando a interdisciplinaridade e a participação coletiva, com objetivo na solução dos problemas ambientais (SOUSA; GOMES; BRITO, 2017).

A percepção e o engajamento do indivíduo acerca da importância dos recursos naturais e aos problemas ambientais locais são um passo de fundamental importância para completar os objetivos da educação ambiental. Para que isso aconteça é necessária uma sintonia entre as diferentes realidades políticas, econômicas, sociais e culturais e também com questões ecológicas. (MELAZO, 2005).

\section{Sustentabilidade}

Com o crescimento do desenvolvimento industrial no final do século XIX - seguido da globalização - trouxe vários fatores provocaram impactos profundos na sociedade. Estes foram observados inicialmente nas esferas ambiental e social, levando as empresas a começarem a adorar ou a se preocupar com a sustentabilidade nas suas atividades organizacionais (DINIZ; CALLADO, 2018).

A sustentabilidade é a forma que a empresa é gerida de maneira a buscar o crescimento e gerar lucro, entendendo as aspirações econômicas e não econômicas das pessoas, quando se pratica a sustentabilidade a organização busca beneficiar os agentes que se encontram no seu macro ambiente fazendo de forma consciente par benefícios futuros (DINIZ; CALLADO, 2018).

A sustentabilidade é o desenvolvimento organizacional que atende às necessidades do presente sem comprometer a habilidade da geração futura atender suas necessidades (DE 
OLIVEIRA, 2015).

Combater a miséria humana e a depreciação agravada da natureza formam os principais pressupostos da sustentabilidade, que tem como base material as estruturas que geram inclusão social, emprego e renda, e melhoria de qualidade de vida. Ela se encontra em processo de construção e legitimação técnica aos processos socioeconômicos das regiões (DE FREITAS; DA SILVA FREITAS, 2016).

O processo de desenvolvimento sustentável para que ocorra na realidade é preciso constituir de três principais fatores: o desenvolvimento econômico, o desenvolvimento social e cultural da população e a preservação ambiental realizados simultaneamente. Tais fatores são peças fundamentais para a qualidade de vida da população atual e futura. A figura a seguir mostra claramente o princípio do desenvolvimento sustentável (MELAZO, 2005).

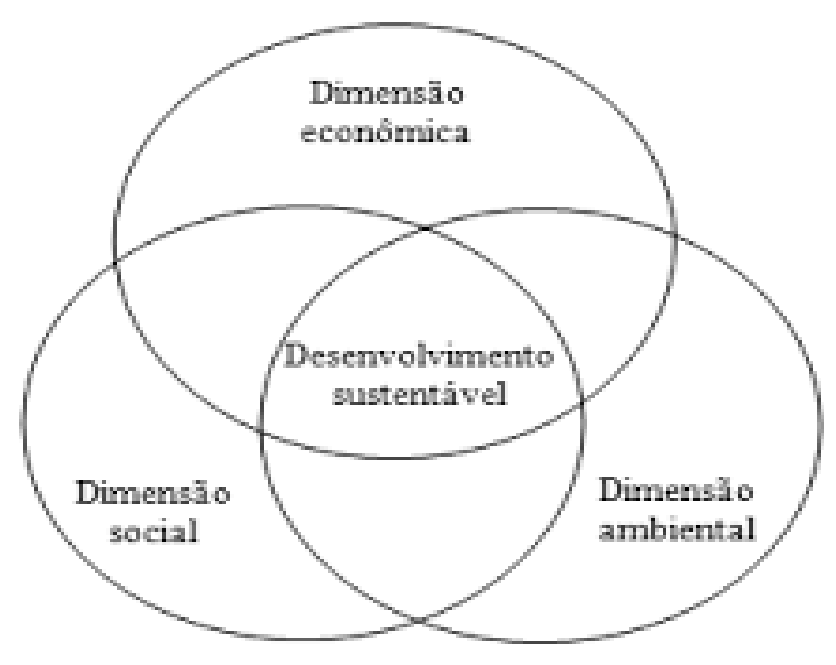

Figura 1-desenvolvimento sustentável. Fonte: Melazo (2005)

A sustentabilidade estimula as responsabilidades éticas, dando ênfase nos aspectos extra econômicos, considerando os aspectos relacionados com a equidade, a justiça social e a ética dos seres vivos, implica, portanto, uma inter-relação necessária de qualidade de vida, equilíbrio ambiental e a ruptura com o atual cenário de desenvolvimento (JACOBI, 2003).

$\mathrm{Na}$ área empresarial a sustentabilidade é operacionalizada, regularmente, a partir do conceito Tiplebottomline- TBL, que apresenta as três dimensões da sustentabilidade que são a ambiental, econômica e social. Na esfera ambiental os recursos devem ser utilizados de forma 
a não prejudicar as gerações futuras diminuindo os impactos dos processos produtivos, do ponto de vista econômico é necessário o cuidado da lucratividade da empresa e o não comprometimento do seu desenvolvimento econômico, na esfera social o objetivo maior é a evolução de um mundo mais justo, relacionando todas as partes interessadas na organização (DA ROCHA, 2015).

A busca por indicadores de sustentabilidade ambiental vem crescendo desde a última década, em particularmente a partir de sua segunda metade, os órgãos que mais procuram são os governamentais, não governamentais institutos de pesquisas e universidades em todo mundo, devido ao fato de o tema ser relativamente novo para comunidade acadêmica. Os indicadores são ferramentas utilizadas para auxiliar o monitoramento e desenvolvimento sustentável, tendo sua principal função fornecer informações sobre diversas dimensões do sistema na sociedade (KEMERICH; RITTER; DE BORBA, 2014).

Os indicadores são úteis e executam muitas funções e comunicam ideias e valores, ajudam a levar a tomada de decisões e ações mais eficazes por apresentar as informações de forma agregada para decisão política. Os indicadores contribuem para a avaliação do desempenho ambiental, social, cultural, econômico e institucional para institutos de pesquisa e inovação, uma vez que preconizam em benefício da sociedade (ALVEZ, 2016).

Os sistemas de indicadores de sustentabilidade representam os mecanismos que são adotados para classificar o nível do desenvolvimento sustentável de um espaço territorial ou de certa atividade econômica, eles simplificam as informações sobre fenômenos complexos melhorando o processo de comunicação e gestão, seu objetivo é integrar e considerar informações para que sua significância dique mais aparente (SILVA; CANDIDO, 2016).

\section{Responsabilidade Social}

Questões ambientais são uma das principais abordagens de um projeto de responsabilidade social, quando a empresa propõe métodos para diminuir o seu impacto na sociedade, realizando isso sem qualquer obrigação apenas para tornar a vida das pessoas melhor, ela está sendo socialmente responsável (PEREIRA et al. 2017). 
A responsabilidade Social Empresarial (RSE) vem do compromisso das empresas em colaborar com o desenvolvimento econômico sustentável, trabalhando em parceria com seus colaborados, suas famílias, a população local e a sociedade em geral para a melhoria na sua qualidade de vida de forma que tragam benefícios tanto para a empresa, como também para o desenvolvimento (KREITLON, 2004).

Os consumidores estão cientes de que as organizações, algumas delas, estão dispostas sinceramente em dar algum retorno a sociedade, embora muitas delas apóiam causas sociais apenas por razões egoístas, apenas para obter lucros através do marketing verde (PEREIRA et al. 2017).

\section{Impactos Ambientais}

O desenvolvimento é resultado de um extenso processo de crescimento econômico, com o aumento da produtividade média, da diversificação produtiva e do emprego, esses processos causam a intensificação da industrialização, também se alterarão as questões ambientais e modernizarão os hábitos e costumes da sociedade (CANO, 2018).

De acordo com Silva (2018, p.22) os impactos ambientais "são alterações no ambiente causadas pelas ações do homem no meio em que vive, podendo ser positivos quando se tornam em melhorias para o ambiente em geral ou pode ser negativo, quando causam risco para o ser humano ou para os recursos naturais".

São exemplos de Impacto Ambiental a erosão e poluição do solo, poluição dos rios por materiais tóxicos da indústria, desmatamento, queimadas, esgotos domésticos despejados em rios e afluentes, descarte de dejetos agrícolas em solos ou lagos (SÁNCHEZ, 2015).

É cada vez mais comum o estudo sobre os impactos ambientais havendo conscientização da população e de governantes, assim facilitando o desenvolvimento sustentável e econômico da cidade, estado ou país (SILVA; 2018).

As indústrias são culpadas por provocar vários danos ao meio ambiente e a saúde humana, pois geram gases e resíduos que podem contaminar rios, mares, lagos, ar e solo. Além de contribuir com a devastação de florestas e extinção de espécies nativas (SÁNCHEZ, 2015).

386 Id on Line Rev. Mult. Psic. V.12, N. 42, Supl. 1, p. 378-396, 2018 - ISSN 1981-1179 Edição eletrônica em http://idonline.emnuvens.com.br/id 


\section{Metodologia}

A pesquisa proporcionou uma maior familiaridade com o tema em estudo no qual ainda é pouco conhecido, no entanto o pesquisador não possui conhecimento suficiente para elaborar de forma mais precisa um problema ou hipóteses, caracterizando como uma pesquisa exploratória, conforme mencionado por Gil (2008).

No entanto o estudo possui como objetivos a descrição de determinadas características, percepções e informações sobre o assunto pesquisado da população, identificando também a pesquisa como descritiva, de acordo com Gil (2008).

Para De Sousa et al. (2018), análise quantitativa é definida pelo uso da quantificação nas modalidades de coleta de informação e de técnicas estatísticas, sendo aplicada nos estudos descritivos.

A pesquisa quantitativa busca trazer a realidade e tem o objetivo de informar resultados de acordo com indicadores e outras técnicas estatísticas, tendo assim um resultado mais rápido e facilmente aplicável (DE SOUSA etal. 2018).

A presente pesquisa foi realizada no município de Brejo Santo, localizada as margens da BR-116 no sul do estado do Ceará, a $510 \mathrm{~km}$ da capital Fortaleza, possuindo uma população de 49109 habitantes, tendo a indústria e o comercio como principais atividades econômicas, segundo IBGE (2018).

Para elaboração do estudo será aplicado um questionário estruturado de perguntas fechadas, pois de acordo com Nogueira (2002) esse tipo de questionário permite a aplicação direta e elimina a necessidade de classificar as respostas à posteriori, possui uma tabulação simples com auxílio de computadores.

A amostragem será probabilística, pois todos os elementos da população possuem uma probabilidade maior que zero de ser selecionados, eliminando uma possível influência do pesquisador na obtenção da amostra (MANZATO; SANTOS, 2008).

A amostra será de 270, com um erro amostral de 5\% e com o nível de confiabilidade de $90 \%$ calculada de acordo com Santos, G (2018) pela fórmula $n=N \cdot Z^{2} \cdot p \cdot(1-p) / Z^{2} \cdot p \cdot(1-p)+e$ 2. $(N-1)$. 


\section{Resultados e Discursão}

Conforme mostrado no Gráfico 1 a maioria entrevistados é do sexo masculino com 57\% do total 270 presentes na amostra utilizada.

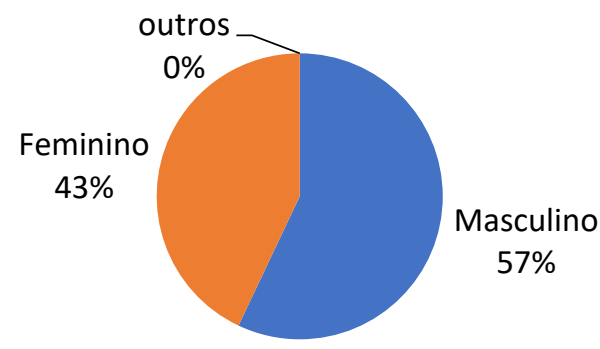

Gráfico: 1

Fonte: Pesquisa de campo realizada pelo autor

Nota-se no gráfico 2 que as faixas etárias propostas pelo pesquisador ouvem entrevistados, mostrando que a pesquisa trouxe percepções sobre todas as idades. A maioria dos entrevistados tem uma faixa etária de 26 a 32 aos com o percentual de $33 \%$ e a minoria dos entrevistados possuem idades superiores a 18 anos, sendo que representa um total de $14 \%$ da amostra.

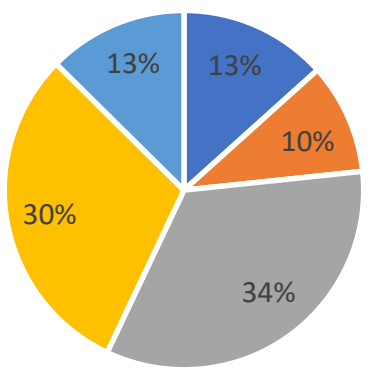

- Até 18 - 19 a $25 \quad 26$ a 32 - 33 a 39 - Acima de 40 anos

Gráfico: 2

Fonte: Pesquisa de campo realizada pelo autor 
O gráfico 3 mostra o grau de escolaridade dos entrevistados, visto que $62 \%$ das pessoas possuem ensino médio completo ou mais.

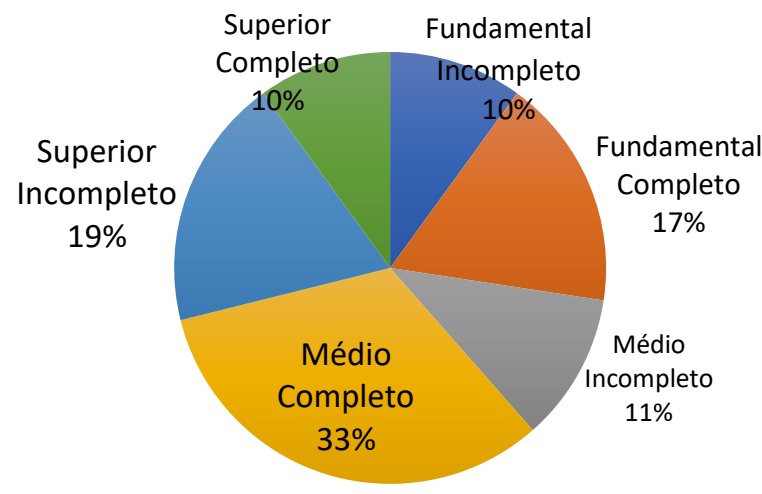

Gráfico: 3

Fonte: Pesquisa de campo realizada pelo autor.

A renda mensal dos entrevistados é disponibilizada no gráfico 4, percebendose assim que a maior porcentagem da população (47\%), tem uma renda mensal de até 1 salário mínimo.
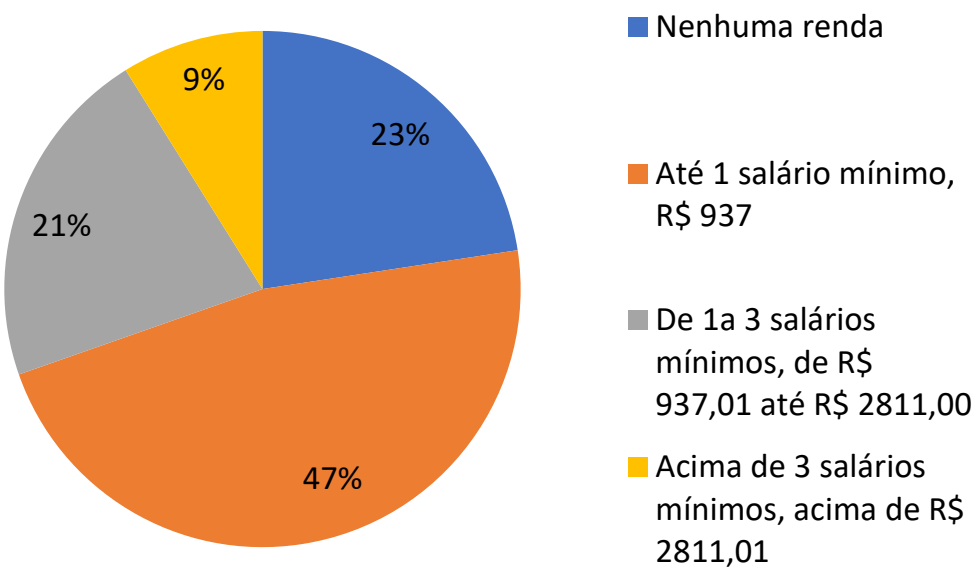

Gráfico: 4

Fonte: Pesquisa de campo realizada pelo autor.

Quando questionados se tinham conhecimento sobre o que é impacto ambiental a maioria dos entrevistados $(71 \%)$, responderam que sim, mostrando que estão conscientizados 
sobre questões ambientais, sendo que isto é de fundamental importância para que a cidade tenha um desenvolvimento socioeconômico considerado, conforme mencionado por Silva (2018).

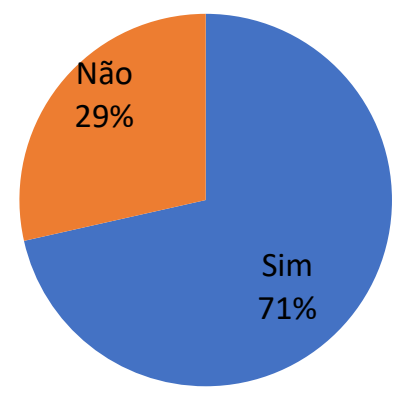

Gráfico 5

Fonte: Pesquisa de campo realizada pelo autor

A maioria dos entrevistados (43\%) acha que as indústrias calçadistas instaladas na cidade pode sim provocar alguma alteração ambiental, conforme mostrado no gráfico 6 , confirmando assim, a idéia de Sánchez (2015), que as indústrias podem provocar danos ao meio ambiente e a saúde humana se não forem feito os procedimentos adequados de gestão ambiental.

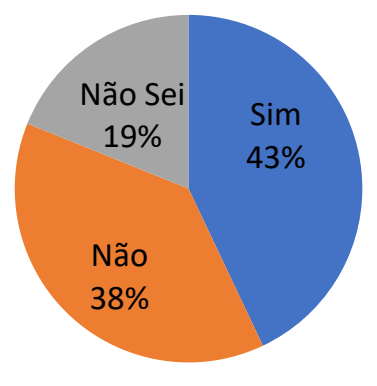

Gráfico: 6

Fonte: Pesquisa de campo realizada pelo autor

Quando abordados sobre o assunto de impactos ambientais $43 \%$ das pessoas dizem não perceber nenhum tipo de agressão ao meio ambiente vindo de tais indústrias calçadistas, sendo 
que $29 \%$ não souberam responder e que $28 \%$ dizem perceber agressões ao meio ambiente vindo dessas indústrias, conforme mostrado pelo gráfico 7 .

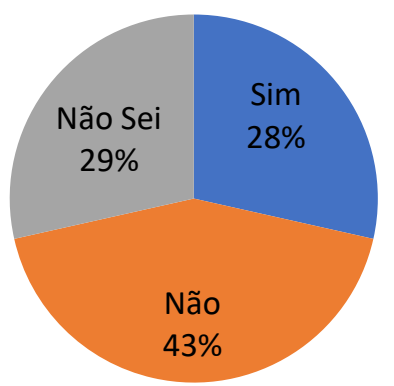

Gráfico: 7

Fonte: Pesquisa de campo realizada pelo autor

Quando perguntados sobre quais outros benefícios essas indústrias trouxeram para a cidade além de emprego e renda, apenas $10 \%$ afirmaram que não trouxeram nada além desses benefícios, mas, como mostrado no gráfico $8,76 \%$ afirmaram que sim, tais indústrias trouxeram vários outros benefícios, conforme mencionado por Cano (2018) a industrialização trará desenvolvimento e modernização dos hábitos e costumes da sociedade.

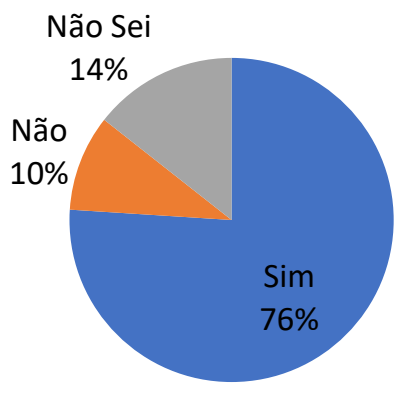

Gráfico:8

Fonte: Pesquisa de campo realizada pelo autor

O gráfico 9 apresenta dados sobre projetos sociais realizados na cidade pelas empresas em estudo, apenas $9 \%$ responderam que sim, existem projetos sociais desenvolvidos por tais 
empresas, porém 91\% dos entrevistados afirmam que não, ou não sabem se existem esses projetos sociais na cidade realizados por essas empresas.

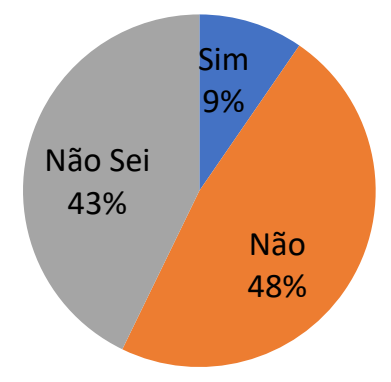

Gráfico: 9

Fonte: Pesquisa de campo realizada pelo autor

Apenas $15 \%$ dos entrevistados afirmara que as empresas promovem ações a estimular os moradores a protegerem o meio ambiente, e $85 \%$ dizem que não estimulam ou não sabem afirmar se de fato essas industrias promovem esse tipo de ação, comforme apresentado no gráfico 10.

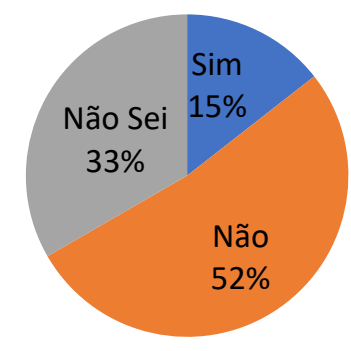

Gráfico: 10

Fonte: Pesquisa de campo realizada pelo autor

Quando questionados sobre qual seguimento é considerado o principal responsável pelos danos ao meio ambiente a maioria (76\%) responderam que a sociedade em geral é responsável, seguindo do setor industrial (14\%), mostrado no gráfico 11. Cada pessoa percebe, reage e responde de forma diferente às ações do o ambiente em que vive assim a sua percepção ambiental compreende que tem de protegê-lo e cuidá-lo. Conforme Fernandes et al. 2004. 


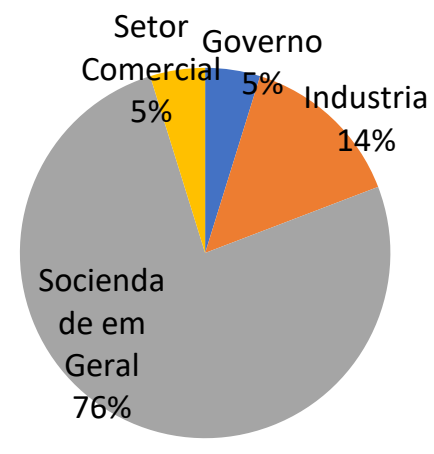

Gráfico: 11

Fonte: Pesquisa de campo realizada pelo autor

\section{Considerações Finais}

O Município de Brejo Santo/Ceará vem passando pelo processo de industrialização com a chegada de algumas indústrias do setor calçadistas, e as pessoas e serviço público municipal tendo que se adaptarem a essa nova realidade atual, tendo em vista a percepção que cada morador dessa cidade tem sobre meio ambiente e responsabilidade social.

A percepção que a população local tem à respeito dos impactos socioambientais provocados após as instalações das indústrias calçadistas no município é muito restrita na maioria das pessoas, tendo em vista a quantidade de "não sei" que muitos dos entrevistados responderam, em contra partida uma parcela desses entrevistados tem sua educação ambiental considerável, juntamente com sua percepção de riscos e benefícios impostos por esse processo de industrialização, atingindo assim o objetivo geral da pesquisa.

Apesar da maioria dos entrevistados terem uma visão restrita a esse processo de industrialização, fica nítido que tais indústrias não usam da estratégia de promoverem ações socioambientais, sendo que neste ponto não houve mudanças e nem qualquer alteração a serem percebidas pela sociedade, concluindo-se os objetivos secundários. 
Vale ressaltar ainda que é importante a pesquisa sobre percepção ambiental, devendo ser explorado em pesquisas futuras a realidade que se vive no meio em que a população esta inserida.

A percepção ambiental é um tema bastante atual e de muita relevância no meio empresarial, como também no meio acadêmico e para a sociedade em geral, necessita ser aprofundado cada vez mais, dessa forma a presente pesquisa começa uma estrada para buscar aprimoramento nas questões sociais, ambientais e econômicas.

\section{Referências}

ALVES, S. F. et al. Indicadores de sustentabilidade para institutos de pesquisa e inovação da área nuclear. BrazilianJournalofRadiationSciences, v. 4, n. 1, 2016.

BARBIERI, José C. Gestão Ambiental empresarial: Conceitos, modelos e instrumentos. São Paulo: Saraiva, 2004.

CANO, Wilson. (Des) industrialização e (Sub) desenvolvimento. Cadernos do Desenvolvimento, v. 9, n. 15 , p. $139-174,2018$.

CARIRI é o maior polo calçadista do nordeste. Diário do nordeste, Fortaleza, 30 abr. 2011. Disponível em: <http://diariodonordeste.verdesmares.com.br/cadernos/negocios/cariri-e-o-maior-polo-calcadistado-nordeste-1.315364>. Acesso em: 21 maio. 2018

DA CUNHA KEMERICH, P. D.; RITTER, L. G.; DE BORBA, W. F. Indicadores de sustentabilidade ambiental: métodos e aplicações. Revista Monografias Ambientais, v. 13, n. 4, p. 3718-3722, 2014.

DA ROCHA, A. C. et al. Gestão Sustentável da Cadeia de Suprimentos e Desempenho Inovador: um estudo multicaso no setor mineral brasileiro. RAI-Revista de Administração e Inovação, v. 12, n. 2, p. 293-316, 2015.

DE FERREIRA, S. F. M.; DE MIRANDA, A. C.; GOMES, H. P. UM ESTUDO DE UMA COMUNIDADE DE TRABALHADORES EM SALINAS: O IMPACTO AMBIENTAL E UMA PROPOSTA EM EDUCAÇÃO AMBIENTAL. Revista Científica ANAP Brasil, v. 8, n. 10, 2015.

DE FREITAS, M; DA SILVA FREITAS, M. C. A sustentabilidade como paradigma: cultura, ciência e cidadania. Editora Vozes Limitada, 2016.

DE OLIVEIRA, E. L.; QUERIDO OLIVEIRA, E. A. A.; FRANCHI CARNIELLO, M. O Barômetro da Sustentabilidade aplicado ao município de Taubaté-SP. Desenvolvimento em Questão, v. 13, n. 30, 2015. 
DE SOUZA, B. C., PINTO, G. A., PAULA, P. P., LOBO, R. J.,\& SOUZA, F. V. P. Implantação do programa $5 \mathrm{~S}$ através da metodologia DMAIC. BrazilianJournalofDevelopment, v. 4, n. 5, p. 2163$2179,2018$.

DIAS, K. C.; DA CRUZ, H. A. Uma Análise Da Percepção E Satisfação Dos Clientes Da Empresa Fpj Comunicações Em Anitápolis/SC.XII Simpósio de Excelência em Gestão e Tecnologia, 2015.

DINIZ, M. L. F.; CALLADO, A. L. C. Mensurando A Sustentabilidade Empresarial Através Do Grid De Sustentabilidade Empresarial (GSE): Um Estudo Em Empresas Do Setor Gráfico. Amazônia, Organizações e Sustentabilidade, v. 6, n. 2, p. 105-122, 2018.

FERNANDES, R. S. et al. Uso da percepção ambiental como instrumento de gestão em aplicações ligadas às áreas educacional, social e ambiental. Encontro Nacional de Pós-Graduação e Pesquisas em Ambiente e Sociedade, v. 2, n. 1, p. 1-15, 2004.

GIL, A. C.Como elaborar projetos de pesquisa. 5. ed. São Paulo: Atlas, 2008.

GODOY, A. S., Pesquisa qualitativa: tipos fundamentais. Revista de Administração de Empresas, São Paulo, v. 35, n.3, p.20-9, mai./jun 1995.

JABBOUR, C. J. C. et al. Gestão ambiental e estrutura organizacional: estudo de múltiplos casos. REGE-Revista de Gestão, v. 19, n. 3, p. 361-375, 2012.

JACOBI, P. R. Educação ambiental, cidadania e sustentabilidade. Cadernos de pesquisa, n. 118, p. 189-205, 2003.

KREITLON, Maria Priscilla. A ética nas relações entre empresas e sociedade: fundamentos teóricos da responsabilidade social empresarial. Encontro anual da Anpad, v. 28, 2004.

MANZATO, A. J; SANTOS, A.B.A Elaboração de Questionários na Pesquisa Quantitativa. Departamento de Ciência de Computação e Estatística- IBILCE- UNERC. 2008.

MARANHÃO, Romero de Albuquerque. Desenvolvimento de capacidades dinâmicas a partir de sistemas de gestão ambiental: um estudo em organizações militares da marinha do Brasil. 2016. Tese de Doutorado.

MELAZO, Guilherme Coelho. Percepção ambiental e educação ambiental: uma reflexão sobre as relações interpessoais e ambientais no espaço urbano. Olhares \& Trilhas, 2005.

MELLO, E. P.; CONEJERO, M. A.; CÉSAR, A. S. Diagnóstico da gestão ambiental nas micro e pequenas empresas: um estudo multicasos na região de Campo Limpo Paulista-SP. REUNA, v. 21, n. 1 , p. $53-74,2015$.

MONTEIRO, J.HP; FIGUEIREDO, C.E.M; MAGALHÃES, A.F.; MELO, M.A.F.; BRITO, J.C.X; ALMEIDA, T.P.L; MANSUR, G.L. Manual de gerenciamento integrado de resíduos sólidos. Rio de Janeiro: BAM, 2001.

NILSSON, W. R. Services instead of products: experiences from energy markets - examples from Sweden. In: MEYER-KRAHMER, F. (Ed.). Innovation and sustainable development: lessons for innovation policies.Heidelberg: Physica-Verlag, 1998. 
NOGUEIRA, R. Elaboração e Análise de Questionários: Uma Revisão da Literatura Básica e a Aplicação dos Conceitos a um Caso Real, Rio de Janeiro: UFRJ/COPPEAD, 2002.

PEREIRA, A. C.; DA SILVA, G. Z.; CARBONARI, Maria Elisa Ehrhardt. Sustentabilidade, responsabilidade social e meio ambiente. 1 ed. São Paulo: Editora Saraiva, 2017.

RABELO, W. A.; DE C ALVES, M. A. Implantação De Sistema De Gestão Ambiental Em Uma Indústria De Laticínios. Águas Subterrâneas, 2016.

SÁNCHEZ, L. E. Avaliação de impacto ambiental. 2 ed. São Paulo: Oficina de Textos, 2015.

SANTOS, G. E. O. Cálculo amostral: calculadora online. [S.l.]: [s.n.], [20--]. Disponível em: <https://www.publicacoesdeturismo.com.br/calculoamostral/>. Acesso em: 10 out. 2018.

SANTOS, Weslley Vieira dos. Percepção ambiental e climática: Estudo de Caso em escolas públicas de Itajubá-MG. 2018.

SCHENINI, P. C. (Org.) Gestão empresarial socioambiental. Florianópolis:(s.n.), 2005.

SILVA, N. C.; CÂNDIDO, G. A. Sistema de indicadores de sustentabilidade do desenvolvimento do turismo: um estudo de caso do município de Areia-PB. Revista Brasileira de Pesquisa em Turismo, v. 10, n. 3, p. 475-496, 2016.

SILVA, T. O. O que é impacto ambiental; Brasil Escola. Disponível em $<$ https://brasilescola.uol.com.br/o-que-e/geografia/o-que-e-impacto-ambiental.htm>. Acesso em $22 \mathrm{de}$ outubro de 2018.

SOUSA, T; GOMES, M. V. T.; BRITO, M. F. Guedes de. A percepção dos pescadores e a educação ambiental como subsídios para a conservação do Baixo São Francisco. Ecologias Humanas: revista da Sociedade Brasileira de Ecologia Humana, 2017.

\section{Como citar este artigo (Formato ABNT):}

PATRICIO, Jairo Grangeiro; LIMA, Raniel Silva. A Percepção dos Moradores Locais sobre os Impactos Socioambientais Gerados Após as Instalações das Indústrias Calçadistas no Município de Brejo Santo-CE. Id on Line Rev.Mult. Psic., 2018, vol.12, n.42, Supl. 1, p. 378-396. ISSN: 1981-1179.

Recebido: 07/11/2018;

Aceito: 08/11/2018. 


\section{APÊNDICE 1}

1.Sexo.
( ) Masculino
( ) Feminino
( ) Outros
2. Idade.
( )Até 18 anos ( )19 à 25 anos ( )26 à 32 anos ( )33 à 39 anos ( )acima de 40 anos
3. Grau de escolaridade.
( ) Fundamental incompleto ( ) Fundamental completo ( )Médio incompleto ( ) Médio completo ( ) Superior incompleto ( ) Superior completo

4. Renda

( )Nenhuma renda

( )Até 1 salário mínimo, R $\$ 937$

( )De 1a 3 salários mínimos, de $\mathrm{R} \$ 937,01$ até $\mathrm{R} \$ 2811,00$

( ) Acima de 3 salários mínimos, acima de $\mathrm{R} \$ 2811,01$

5.Você sabe o que é Impacto Ambiental?
( ) $\mathrm{Sim}$
( ) Não
( ) Outros

6. As indústrias calçadistas instaladas na cidade podem provocar alguma alteração Ambiental?
( ) $\operatorname{Sim}$
( ) Não
( ) Não sei

7. Você consegue perceber se houve alguma alteração ambiental que tenha sido provocada pelas atividades industriais calçadistas na cidade?
( ) Sim
( ) Não
( ) Não sei

8 .Além de emprego e geração de renda, as indústrias trouxeram outros benefícios para a cidade?
( ) $\mathrm{Sim}$
( ) Não
( ) Não sei

9. As indústrias instaladas na cidade realizam com a população projetos sociais?
( ) Sim
( ) Não
( ) Não sei

10.As indústrias instaladas na cidade promovem atividades que estimulem a população a protegerem o meio ambiente?
( ) Sim
( ) Não
( ) Não sei

11. Qual o segmento você considera como principal responsável pelos danos ao meio ambiente?

( ) O governo ( ) A indústria ( ) A sociedade em geral ( ) Setor comercial 